\title{
Are Securities Also Derivatives?
}

\author{
Kuoping Chang \\ Department of Quantitative Finance, National Tsing Hua University, Hsinchu, Taiwan \\ Email: kpchang@mx.nthu.edu.tw
}

Received May 21, 2012; revised June 20, 2012; accepted July 8, 2012

\begin{abstract}
This paper has used the Arbitrage Theorem (Gordan Theorem) to show that first, all securities are derivatives for each other, and they are priced by the same risk neutral probability measure. Second, after the firm changes its debt-equity ratio, the equityholders can always combine the new equity with other existing securities to create a home-made equity which will give exactly the same time-1 payoff of the old equity. That is, we have a capital structure irrelevancy proposition: changes in firms' debt-equity ratios will not affect equityholders' wealth (welfare), and equityholders' preferences toward variance are irrelevant. Third, when the firm moves from a more certain project to a more uncertain one, the time- 0 price of equity will increase, but (because the time-1 payoff of common bond has an upper bound) the time- 0 price of common bond will decrease. Fourth, different labor contractual arrangements will not affect the time- 0 price of labor input. When the firm moves from a more certain project to a more uncertain one, the time- 0 price of labor input will increase if it is under the share or the mixed contract.
\end{abstract}

Keywords: Arbitrage Theorem; Derivatives; Home-Made Security; Capital Structure Irrelevancy; Share and Mixed Labor Contracts

\section{Introduction}

The seminal work of Black and Scholes (1973) has inspired many researches on pricing and hedging different financial contracts [1]. The literature argues that options and their underlying assets are different: a rise in the variability of the underlying asset will decrease its market value, but this rise will increase the market value of the option. Some studies also argue that an option value depends only on its underlying asset, and it does not depend on the random prices of other securities or portfolios. I think these arguments are wrong. In this paper, I first derive the Arbitrage Theorem, and then use the theorem to show that all securities are derivatives for each other, and they depend on each other. The paper also derives a capital structure irrelevancy proposition: changes in firms' debt-equity ratios will not affect equityholders' wealth (welfare), and equityholders' preferences toward variance are irrelevant. When the firm moves from a more certain project to a more uncertain one, the time- 0 price of equity will increase, but the time- 0 price of common bond will decrease. Different labor contractual arrangements will not affect the time- 0 price of labor input. When the firm moves from a more certain project to a more uncertain one, the time- 0 price of labor input will increase if it is under the share or the mixed contract.

The remainder of this paper is organized as follows.
Section 2 derives the Arbitrage Theorem and uses the theorem and several examples to show that securities are derivatives for each other; and that after the firm changes its debt-equity ratio, the equityholders can always combine the new equity with other existing securities to create a home-made equity which will give exactly the same time-1 payoff of the old equity. Concluding remarks appear in Section 3.

\section{Arbitrage Theorem and Valuation of Contracts}

Theorem 1:

Let $S$ be a nonempty, closed convex set in $R^{n}$ and $\mathbf{y} \notin S$. Then, there exists a unique point $\overline{\mathbf{x}} \in S$ with minimum distance from $\mathbf{y}$. Also, $\overline{\mathbf{x}}$ is the minimizing point if and only if $(\mathbf{y}-\overline{\mathbf{x}})^{t}(\mathbf{x}-\overline{\mathbf{x}}) \leq 0$ for all $\mathbf{x} \in S$.

Proof

We first show the existence of a minimum point. Since $S$ is not empty, there exists a point $\hat{\mathbf{x}} \in S$. Define $\bar{S}=S \cap\{\mathbf{x}:\|\mathbf{y}-\mathbf{x}\| \leq\|\mathbf{y}-\hat{\mathbf{x}}\|\}$ and hence,

$$
\inf \{\|\mathbf{y}-\mathbf{x}\|: \mathbf{x} \in S\}=\inf \{\|\mathbf{y}-\mathbf{x}\|: \mathbf{x} \in \bar{S}\} .
$$

Since $\inf \{\|\mathbf{y}-\mathbf{x}\|: \mathbf{x} \in \bar{S}\}$ means finding the minimum of a continuous function over a nonempty, compact set $\bar{S}$, by Weierstrass' theorem, there exists a minimizing point $\overline{\mathbf{x}}$ in $S$ that is closest to the point $\mathbf{y}$.

To show the uniqueness of minimum point, suppose 
that there is another $\overline{\mathbf{x}}^{\prime} \in S$ which is also a minimum point, i.e., $\left\|\mathbf{y}-\overline{\mathbf{x}}^{\prime}\right\|=\|\mathbf{y}-\overline{\mathbf{x}}\| \equiv \gamma$. By convexity of $S$, $\left(\overline{\mathbf{x}}+\overline{\mathbf{x}}^{\prime}\right) / 2 \in S$. By Schwartz inequality, we get

$$
\left\|\mathbf{y}-\frac{\overline{\mathbf{x}}+\overline{\mathbf{x}}^{\prime}}{2}\right\| \leq \frac{1}{2}\|\mathbf{y}-\overline{\mathbf{x}}\|+\frac{1}{2}\left\|\mathbf{y}-\overline{\mathbf{x}}^{\prime}\right\|=\gamma
$$

If strict inequality holds, we have a contradiction to $\overline{\mathbf{x}}$ being the closest point to $\mathbf{y}$. Therefore, equality holds, and we must have $\mathbf{y}-\overline{\mathbf{x}}=\lambda\left(\mathbf{y}-\overline{\mathbf{x}}^{\prime}\right)$ for some $\lambda$. Since $\|\mathbf{y}-\overline{\mathbf{x}}\|=\left\|\mathbf{y}-\overline{\mathbf{x}}^{\prime}\right\|=\gamma,|\lambda|=1$. If $\lambda=-1$, then

$$
\mathbf{y}=\frac{\overline{\mathbf{x}}+\overline{\mathbf{x}}^{\prime}}{2} \in S
$$

which contradicts the assumption $\mathbf{y} \notin S$. Thus, $\lambda=1$, and we have $\overline{\mathbf{x}}^{\prime}=\overline{\mathbf{x}}$.

Suppose $(\mathbf{y}-\overline{\mathbf{x}})^{t}(\mathbf{x}-\overline{\mathbf{x}}) \leq 0$ for all $\mathbf{x} \in S$. Then,

$$
\begin{aligned}
\|\mathbf{y}-\mathbf{x}\|^{2}= & \|\mathbf{y}-\overline{\mathbf{x}}+\overline{\mathbf{x}}-\mathbf{x}\|^{2} \\
= & \|\mathbf{y}-\overline{\mathbf{x}}\|^{2}+\|\overline{\mathbf{x}}-\mathbf{x}\|^{2} \\
& +2(\mathbf{y}-\overline{\mathbf{x}})^{t}(\overline{\mathbf{x}}-\mathbf{x})
\end{aligned}
$$

Since $\|\overline{\mathbf{x}}-\mathbf{x}\|^{2} \geq 0$ and $(\mathbf{y}-\overline{\mathbf{x}})^{t}(\overline{\mathbf{x}}-\mathbf{x}) \geq 0$ by assumption, $\|\mathbf{y}-\overline{\mathbf{x}}\|^{2} \leq\|\mathbf{y}-\mathbf{x}\|^{2}$ for all $\mathbf{x} \in S$, i.e., $\overline{\mathbf{x}}$ is the minimizing point. Conversely, assume that $\overline{\mathbf{x}}$ is the minimizing point. Let $\mathbf{x} \in S$ and $0 \leq \alpha \leq 1$. We have

$$
\alpha \mathbf{x}+(1-\alpha) \overline{\mathbf{x}}=\overline{\mathbf{x}}+\alpha(\mathbf{x}-\overline{\mathbf{x}}) \in S
$$

and $\|\mathbf{y}-\overline{\mathbf{x}}-\alpha(\mathbf{x}-\overline{\mathbf{x}})\|^{2} \geq\|\mathbf{y}-\overline{\mathbf{x}}\|^{2}$. Therefore, from

$$
\begin{aligned}
\|\mathbf{y}-\overline{\mathbf{x}}-\alpha(\mathbf{x}-\overline{\mathbf{x}})\|^{2}= & \|\mathbf{y}-\overline{\mathbf{x}}\|^{2}+\alpha^{2}\|\mathbf{x}-\overline{\mathbf{x}}\|^{2} \\
& -2 \alpha(\mathbf{y}-\overline{\mathbf{x}})^{t}(\mathbf{x}-\overline{\mathbf{x}})
\end{aligned}
$$

we can get $2 \alpha(\mathbf{y}-\overline{\mathbf{x}})^{t}(\mathbf{x}-\overline{\mathbf{x}}) \leq \alpha^{2}\|\mathbf{x}-\overline{\mathbf{x}}\|^{2}$ for all $0 \leq \alpha$ $\leq 1$. Dividing this inequality by any such $\alpha>0$ and letting $\alpha \rightarrow 0^{+}$, we have $(\mathbf{y}-\overline{\mathbf{x}})^{t}(\mathbf{x}-\overline{\mathbf{x}}) \leq 0$ for all $\mathbf{x} \in S$.

Theorem 2 (Separating Hyperplane Theorem):

Let $S$ be a nonempty, closed convex set in $R^{n}$ and $\mathbf{y} \notin S$. Then, there exists a nonzero vector $\mathbf{z} \in R^{n}$ and a scalar $\alpha$ such that $\mathbf{z}^{t} \mathbf{y}<\alpha$ and $\mathbf{z}^{t} \mathbf{x} \geq \alpha$ for each $\mathbf{x} \in S$.

\section{Proof}

From Theorem 1 we know that because the set $S$ is a nonempty, closed convex set in $R^{n}$ and $\mathbf{y} \notin S$, there exists a unique minimizing point $\overline{\mathbf{x}}$ that

$$
(\mathbf{y}-\overline{\mathbf{x}})^{t}(\mathbf{x}-\overline{\mathbf{x}}) \leq 0 \text { for all } \mathbf{x} \in S .
$$

Letting $\mathbf{z}=-(\mathbf{y}-\overline{\mathbf{x}})$ and $\alpha=\mathbf{z}^{t} \overline{\mathbf{x}}$, we have $\mathbf{z}^{t}(\mathbf{x}$ $-\overline{\mathbf{x}}) \geq 0$ and hence, $\mathbf{z}^{t} \mathbf{x} \geq \alpha$ for each $\mathbf{x} \in S$. Also, $\mathbf{z}^{t} \mathbf{y}-$ $\boldsymbol{\alpha}=\mathbf{z}^{t}(\mathbf{y}-\overline{\mathbf{x}})=-(\mathbf{y}-\overline{\mathbf{x}})^{t}(\mathbf{y}-\overline{\mathbf{x}})<0$ or $\mathbf{z}^{t} \mathbf{y}<\alpha$.

Theorem 3 (Farkas Theorem):

Let $\mathbf{A}$ be an $m \times n$ matrix and $\mathbf{c} \in R^{n}$ be a vector. Then, exactly one of the following systems has a solution:
System 1: $\mathbf{A x} \geq 0$ and $\mathbf{c}^{t} \mathbf{x}<0$ for some $\mathbf{x} \in R^{n}$

System $2: \mathbf{A}^{t} \mathbf{y}=\mathbf{c}$ and $\mathbf{y} \geq 0$ for some $\mathbf{y} \in R^{m}$

Proof

1) Suppose that System 2 has a solution; that is, there exists a $\mathbf{y} \in R^{m}$ and $\mathbf{y} \geq 0$ such that $\mathbf{A}^{t} \mathbf{y}=\mathbf{c}$. Then, if for any $\quad \mathbf{x} \in R^{n}$ such that $\mathbf{A x} \geq 0$, then $\mathbf{c}^{t} \mathbf{x}=\mathbf{y}^{t} \mathbf{A} \mathbf{x} \geq 0$; that is, System 1 has no solution.

2) Suppose System 2 has no solution. Form the set $S=\left\{\mathbf{x}^{\prime}: \mathbf{x}^{\prime}=\mathbf{A}^{t} \mathbf{y}, \mathbf{y} \geq 0\right\}$. Note that the set $S$ is a closed convex set: Let $\mathbf{x}_{1}, \mathbf{x}_{2} \in S$ and $\beta \in[0,1]$. Then there must exist $\mathbf{y}_{1}, \mathbf{y}_{2} \geq 0$ such that $\mathbf{x}_{1}=\mathbf{A}^{t} \mathbf{y}_{1}$ and $\mathbf{x}_{2}=\mathbf{A}^{t} \mathbf{y}_{2}$. Also,

$$
\begin{aligned}
\beta \mathbf{x}_{1}+(1-\beta) \mathbf{x}_{2} & =\beta \mathbf{A}^{t} \mathbf{y}_{1}+(1-\beta) \mathbf{A}^{t} \mathbf{y}_{2} \\
& =\mathbf{A}^{t}\left[\beta \mathbf{y}_{1}+(1-\beta) \mathbf{y}_{2}\right] \geq \mathbf{0}
\end{aligned}
$$

where $\beta \mathbf{y}_{1}+(1-\beta) \mathbf{y}_{2} \geq 0$.

Since $\mathbf{c} \notin S$, by Theorem 2, there exists a nonzero vector $\mathbf{z} \in R^{n}$ and a scalar $\alpha$ such that $\mathbf{z}^{t} \mathbf{c}<\alpha$ and $\mathbf{z}^{t} \mathbf{x}^{\prime} \geq \alpha$ for each $\mathbf{x}^{\prime} \in S$. Because $0 \in S, \alpha \leq \mathbf{z}^{t} \mathbf{0}=0$. $\alpha \leq \mathbf{z}^{t} \mathbf{x}^{\prime}=\mathbf{z}^{t} \mathbf{A}^{t} \mathbf{y}=\mathbf{y}^{t} \mathbf{A z}$ for each $\mathbf{y} \geq 0$. Since $\mathbf{y}$ can be made arbitrarily large and $\alpha$ is a fixed number, we must have $\mathbf{A z} \geq 0$. We have therefore constructed a vector $\mathbf{z} \in R^{n}$ such that $\mathbf{A z} \geq 0$ and $\mathbf{z}^{t} \mathbf{c}<0$, i.e., System 1 has a solution.

Theorem 4 (Gordan Theorem or Arbitrage Theorem):

Let $\mathbf{A}$ be an $m \times n$ matrix. Then, exactly one of the following systems has a solution:

System 1: $\mathbf{A x}>0$ for some $\mathbf{x} \in R^{n}$

System 2: $\mathbf{A}^{t} \mathbf{p}=0$ for some $\mathbf{p} \in R^{m}, \mathbf{p} \geq 0, \mathbf{e}^{t} \mathbf{p}=1$

where

$$
\mathbf{e}=\left[\begin{array}{c}
1 \\
1 \\
\vdots \\
1
\end{array}\right] .
$$

Proof

1) Suppose that System 1 has a solution: $\mathbf{A x}>0$ for some $\mathbf{x} \in R^{n}$. Then, we can construct a negative scalar $\delta$ $<0$ and a vector

$$
\mathbf{e}=\left[\begin{array}{c}
1 \\
1 \\
\vdots \\
1
\end{array}\right]
$$

such that $\mathbf{A x}+\delta \mathbf{e} \geq 0$, or $\left[\begin{array}{l}\mathbf{A} \\ \mathbf{e}\end{array}\right]\left[\begin{array}{l}\mathbf{x} \\ \delta\end{array}\right] \geq \mathbf{0}$ and

$$
\left[\begin{array}{lllll}
0 & 0 & \cdots & 0 & 1
\end{array}\right]\left[\begin{array}{l}
\mathbf{x} \\
\delta
\end{array}\right]=\delta<0 .
$$

Define $[\mathbf{A ~ e}]=\mathbf{A}^{\prime},[\mathbf{x} \delta]=\mathbf{x}^{\prime}$, and $[0,0, \cdots, 0,1]=\mathbf{c}^{t}$. We have $\mathbf{A}^{\prime} \mathbf{x}^{\prime} \geq 0, \quad \mathbf{c}^{t} \mathbf{x}^{\prime}<0$ and $\mathbf{x}^{\prime} \in R^{n+1}$; that is, System 1 of Theorem 3 has a solution. 
2) With the same definitions, System 2 of Theorem 3 can be interpreted as: There exists a vector $\mathbf{p} \geq 0$ and $\mathbf{p} \in R^{m}$ such that $\left(\mathbf{A}^{\prime}\right)^{t} \mathbf{p}=\mathbf{c}$. That is,

$$
\left[\begin{array}{c}
\mathbf{A}^{t} \\
\mathbf{e}^{t}
\end{array}\right] \mathbf{p}=\left[\begin{array}{c}
0 \\
0 \\
\vdots \\
0 \\
1
\end{array}\right],
$$

or $\mathbf{A}^{t} \mathbf{p}=0$ and $\mathbf{e}^{t} \mathbf{p}=1$ (i.e., $\sum_{i=1}^{m} p_{i}=1$ ).

In System 2 of the Arbitrage Theorem, the vector $\mathbf{p}$ is usually termed as the risk neutral probability measure, and $p_{i}, i=1, \cdots, m$, can be interpreted as the current price of one dollar received at the end of period if state $i$ occurs. If the matrix A has rank $m$ (i.e., the matrix has $m$ independent rows), the risk neutral probability measure $\mathbf{p}$ will be unique. We now use the Arbitrage Theorem to clarify some ambiguous (and erroneous) arguments in the literature.

Example 1. All Securities Are Derivatives.

Assume a one-period, two states of nature world with no transaction costs. There are a money market (Security 1) which provides $1+0.25$ dollars at time one if one dollar is invested at time 0 (i.e., the interest rate is $r=0.25$ ), and two other securities (Security 2 and Security 3 ) with current prices 4 and 500 dollars, respectively, which provide:

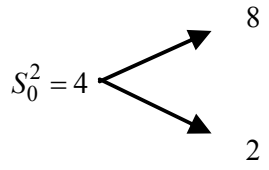

Security 2

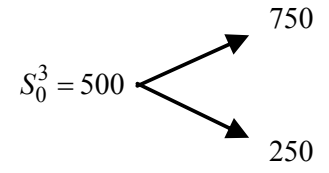

Security 3
Note that the two securities are not governed by the same risk neutral probability measure (i.e., System 2 of the Arbitrage Theorem has no solution):

$$
\left\{\begin{aligned}
\text { Security 2: } S_{0}^{2}= & 4 \frac{1}{1+0.25}\left(\frac{1}{2} \times 8+\frac{1}{2} \times 2\right) ; \\
\mathbf{p}^{\prime} & =\left[\begin{array}{l}
1 / 2 \\
1 / 2
\end{array}\right] \\
\text { Security } 3: S_{0}^{3} & =500=\frac{1}{1+0.25}\left(\frac{3}{4} \times 750+\frac{1}{4} \times 250\right) ; \\
\mathbf{p}^{\prime \prime} & =\left[\begin{array}{l}
3 / 4 \\
1 / 4
\end{array}\right]
\end{aligned}\right.
$$

i.e., we cannot find a vector $\mathbf{p}=\left[\begin{array}{c}\pi \\ 1-\pi\end{array}\right], 0 \leq \pi \leq 1$, such that

$$
\begin{aligned}
& {\left[\begin{array}{ll}
8-4(1+0.25) & 2-4(1+0.25) \\
750-500(1+0.25) & 250-500(1+0.25)
\end{array}\right]\left[\begin{array}{l}
\pi \\
1-\pi
\end{array}\right] } \\
= & {\left[\begin{array}{l}
0 \\
0
\end{array}\right] }
\end{aligned}
$$

By System 1 of the Arbitrage Theorem, arbitrage exists: e.g., at time 0 , we can short sell one share of Security 3 , buy 60 shares of Security 2 and invest $260(=500$ $-4 \times 60$ ) dollars in the money market, and at time 1 we can get net profit:

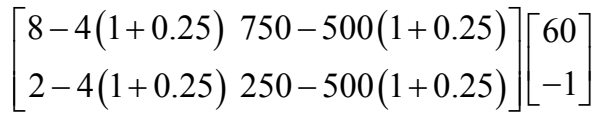

$$
\begin{aligned}
& =\left[\begin{array}{l}
55 \\
195
\end{array}\right]>\left[\begin{array}{l}
0 \\
0
\end{array}\right]
\end{aligned}
$$

Hence, in equilibrium (with no arbitrage), the time-0 prices of Security 2 and Security 3 will change so that they are priced by the same risk neutral probability messure, say,

$$
\mathbf{p}=\left[\begin{array}{l}
3 / 4 \\
1 / 4
\end{array}\right]
$$

and

$$
\left\{\begin{array}{l}
\text { Money Market (Security 1): } S_{0}^{1}=1=\frac{1}{1+0.25}\left(\frac{3}{4} \times 1.25\right. \\
\left.+\frac{1}{4} \times 1.25\right) \\
\text { Security 2: } S_{0}^{2}=5.2=\frac{1}{1+0.25}\left(\frac{3}{4} \times 8+\frac{1}{4} \times 2\right) \\
\text { Security } 3: S_{0}^{3}=500=\frac{1}{1+0.25}\left(\frac{3}{4} \times 750+\frac{1}{4} \times 250\right)
\end{array}\right.
$$

Suppose that two European call options are based on Security 2 (with strike price 4 dollars) and Security 3 (with strike price 650 dollars), respectively:

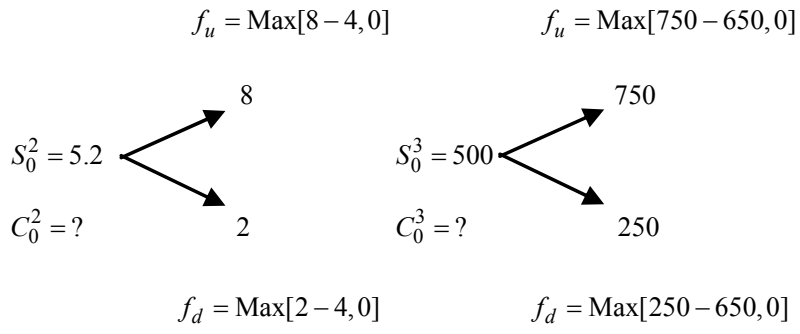

Since all the securities are governed (priced) by the same, unique risk neutral probability measure

$$
\mathbf{p}=\left[\begin{array}{l}
3 / 4 \\
1 / 4
\end{array}\right]
$$

we will have: 
$\left\{\begin{array}{r}\text { Money Market (Security 1): } S_{0}^{1}=1=\frac{1}{1+0.25}\left(\frac{3}{4} \times 1.25\right. \\ \left.+\frac{1}{4} \times 1.25\right)\end{array}\right.$

Security $2: S_{0}^{2}=5.2=\frac{1}{1+0.25}\left(\frac{3}{4} \times 8+\frac{1}{4} \times 2\right)$

Security $3: S_{0}^{3}=500=\frac{1}{1+0.25}\left(\frac{3}{4} \times 750+\frac{1}{4} \times 250\right)$

Security $4: S_{0}^{4}=C_{0}^{2}=2.4=\frac{1}{1+0.25}\left(\frac{3}{4} \times 4+\frac{1}{4} \times 0\right)$

Security $5: S_{0}^{5}=C_{0}^{3}=60=\frac{1}{1+0.25}\left(\frac{3}{4} \times 100+\frac{1}{4} \times 0\right)$
$\vdots$
$\vdots$

Also, at time 0 , by buying $n$ shares of the underlying asset and selling one call to construct a portfolio which gives certain time-1 payoff, the prices of the two European calls can be derived from Security 2 or Security 3:

For $C_{0}^{2}$ :

$$
\begin{aligned}
& \left\{\begin{array}{l}
8(n)-4=2(n)-0 \Rightarrow n=2 / 3 \\
\frac{2(2 / 3)-0}{1+0.25}=5.2(2 / 3)-C_{0}^{2} \Rightarrow C_{0}^{2}=2.4
\end{array}\right. \\
& \left\{\begin{array}{l}
750(n)-4=250(n)-0 \Rightarrow n=0.008 \\
\frac{250(0.008)-0}{1+0.25}=500(0.008)-C_{0}^{2} \Rightarrow C_{0}^{2}=2.4
\end{array}\right.
\end{aligned}
$$

or

For $C_{0}^{3}$ :

$$
\begin{aligned}
& \left\{\begin{array}{l}
750(n)-100=250(n)-0 \Rightarrow n=0.2 \\
\frac{250(0.2)-0}{1+0.25}=500(0.2)-C_{0}^{3} \Rightarrow C_{0}^{3}=60
\end{array}\right. \\
& \left\{\begin{array}{l}
8(n)-100=2(n)-0 \Rightarrow n=50 / 3 \\
\frac{2(50 / 3)-0}{1+0.25}=5.2(50 / 3)-C_{0}^{3} \Rightarrow C_{0}^{3}=60
\end{array}\right.
\end{aligned}
$$

The time- 0 price of Security 2 can be derived from Security 3 or the options, and the time- 0 price of Security 3 can be derived from Security 2 or the options:

For $S_{0}^{2}$ :

$$
\left\{\begin{array}{l}
750(n)-8=250(n)-2 \Rightarrow n=0.012 \\
\frac{250(0.012)-2}{1+0.25}=500(0.012)-S_{0}^{2} \Rightarrow S_{0}^{2}=5.2
\end{array}\right.
$$

${ }^{1}$ This example and the following examples assume complete markets; i.e., the matrix $\mathbf{A}$ of System 2 of Theorem 4 has $m$ independent rows. In incomplete markets, securities may not be derivatives for each other, but with no arbitrage (i.e., System 2 of Theorem 4 has a solution), they will still be priced by the same (which may not be unique) risk neutral probability measure. See Appendix A. or

$$
\left\{\begin{array}{l}
100(n)-8=0(n)-2 \Rightarrow n=0.06 \\
\frac{0(0.06)-2}{1+0.25}=60(0.06)-S_{0}^{2} \Rightarrow S_{0}^{2}=5.2
\end{array}\right.
$$

For $S_{0}^{3}$ :

$$
\left\{\begin{array}{l}
8(n)-750=2(n)-250 \Rightarrow n=250 / 3 \\
\frac{2(250 / 3)-250}{1+0.25}=5.2(250 / 3)-S_{0}^{3} \Rightarrow S_{0}^{3}=500
\end{array}\right.
$$

or

$$
\left\{\begin{array}{l}
4(n)-750=0(n)-250 \Rightarrow n=125 \\
\frac{0(125)-250}{1+0.25}=2.4(125)-S_{0}^{3} \Rightarrow S_{0}^{3}=500
\end{array}\right.
$$

Thus, we can conclude that all securities are derivatives for each other, and all securities are underlying assets for each other. This result refutes Cox, Ross and Rubinstein's (1979) [2] claim that "the only random variable on which the call value depends is the stock itself. In particular, it does not depend on the random prices of other securities or portfolios" (p. 235). ${ }^{1}$

Example 2. Home-made Securities.

In Example 1, assume that Security 3 is a firm and is the sum of five shares of equity:

$$
\begin{aligned}
& \text { Money Market (Security 1): } S_{0}^{1}=1=\frac{1}{1+0.25}\left(\frac{3}{4} \times 1.25\right. \\
& \left.+\frac{1}{4} \times 1.25\right) \\
& \text { Security } 2: S_{0}^{2}=5.2=\frac{1}{1+0.25}\left(\frac{3}{4} \times 8+\frac{1}{4} \times 2\right) \\
& \text { Security 3: }\left\{\begin{aligned}
E_{0}^{1}=100 & =\frac{1}{1+0.25}\left(\frac{3}{4} \times 150+\frac{1}{4} \times 50\right) \\
E_{0}^{2}=100 & =\frac{1}{1+0.25}\left(\frac{3}{4} \times 150+\frac{1}{4} \times 50\right) \\
E_{0}^{3}=100 & =\frac{1}{1+0.25}\left(\frac{3}{4} \times 150+\frac{1}{4} \times 50\right) \\
E_{0}^{4}=100 & =\frac{1}{1+0.25}\left(\frac{3}{4} \times 150+\frac{1}{4} \times 50\right) \\
E_{0}^{5}=100 & =\frac{1}{1+0.25}\left(\frac{3}{4} \times 150+\frac{1}{4} \times 50\right)
\end{aligned}\right. \\
& \text { ! } \quad \vdots
\end{aligned}
$$

Suppose that the fourth and the fifth shares of equity ( $E_{0}^{4}$ and $E_{0}^{5}$ ) of the firm are changed into riskless debts $\left(D_{0}^{4}\right.$ and $\left.D_{0}^{5}\right)$ : 


$$
\text { Security 3: }\left\{\begin{array}{l}
E_{0}^{1^{\prime}}=100=\frac{1}{1+0.25}\left(\frac{3}{4} \times \frac{500}{3}+\frac{1}{4} \times 0\right) \\
E_{0}^{2^{\prime}}=100=\frac{1}{1+0.25}\left(\frac{3}{4} \times \frac{500}{3}+\frac{1}{4} \times 0\right) \\
D_{0}^{4}=100=\frac{1}{1+0.25}\left(\frac{3}{4} \times \frac{500}{3}+\frac{1}{4} \times 0\right) \\
D_{0}^{5}=100=\frac{1}{1+0.25}\left(\frac{3}{4} \times 125+\frac{1}{4} \times 125\right)
\end{array}\right.
$$

The market value of the firm (Security 3 ) at time 0 is still 500 dollars; that is, the market value of firm is independent of its debt-equity ratio. This is just a restatement of Modigliani-Miller's first proposition. ${ }^{2}$

Comparing Equation (1) with Equation (2), it is found that more debt means higher variance of equity's time-1 payoff:

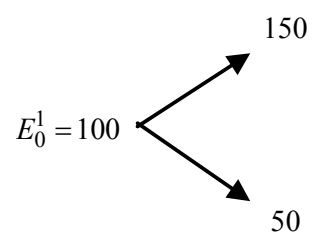

No Debt

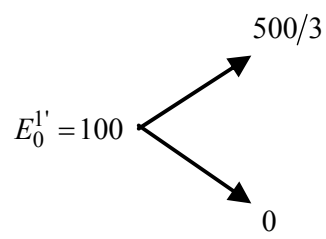

With Debt
But after the firm changes its debt-equity ratio, the equityholders can always buy only 0.6 shares of the new equity $\left(E_{0}^{1^{\prime}}\right)$ and invest $40(=100-0.6 \times 100)$ dollars in the money market to recreate the time-1 payoff of the old equity $\left(E_{0}^{1}\right)$ :

$$
\left\{\begin{array}{l}
150=(0.6)(500 / 3)+(1+0.25)(100-0.6 \times 100) \\
50=(0.6)(0)+(1+0.25)(100-0.6 \times 100)
\end{array}\right.
$$

or

$$
\left[\begin{array}{l}
150 \\
50
\end{array}\right]=(0.6)\left[\begin{array}{c}
\frac{500}{3} \\
0
\end{array}\right]+(100-0.6 \times 100)\left[\begin{array}{l}
1.25 \\
1.25
\end{array}\right]
$$

Suppose that in Equation (2), debts are risky:

${ }^{2}$ For a simpler proof of this proposition without using any math, see Chang (2004) [3].

${ }^{3}$ Note that even before the firm changes its debt-equity ratio, the equityholders can buy $3 / 2$ shares of the existing equity ( $\left.E_{0}^{1}\right)$ and borrow $60\left(=100 \times \frac{3}{2}-90\right)$ dollars from the money market to create the time- 1 payoffs of the new equity $\left(E_{0}^{1^{\prime \prime}}\right)$ :

$$
\left\{\begin{array}{l}
450 / 3=(3 / 2)(150)+(1+0.25)(90-(3 / 2) \times 100) \\
0=(3 / 2)(50)+(1+0.25)(90-(3 / 2) \times 100)
\end{array} .\right.
$$

$$
\text { Security 3: }\left\{\begin{array}{l}
E_{0}^{1^{\prime \prime}}=90=\frac{1}{1+0.25}\left(\frac{3}{4} \times \frac{450}{3}+\frac{1}{4} \times 0\right) \\
E_{0}^{2^{\prime \prime}}=90=\frac{1}{1+0.25}\left(\frac{3}{4} \times \frac{450}{3}+\frac{1}{4} \times 0\right) \\
D_{0}^{4^{\prime \prime}}=115=\frac{1}{1+0.25}\left(\frac{3}{4} \times \frac{450}{3}+\frac{1}{4} \times 0\right) \\
D_{0}^{5^{\prime}}=115=\frac{1}{1+0.25}\left(\frac{3}{4} \times 150+\frac{1}{4} \times 125\right)
\end{array}\right.
$$
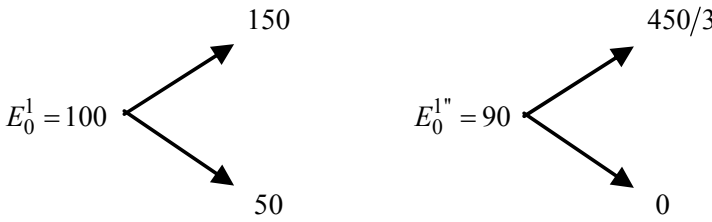

Again, after the firm changes its debt-equity ratio, the equityholders can always buy $2 / 3$ shares of the new equity $\left(E_{0}^{1 "}\right)$ and invest $40(=100-(2 / 3) \times 90)$ dollars in the money market to recreate the time-1 payoff of the old equity $\left(E_{0}^{1}\right)$ :

$$
\begin{gathered}
\left\{\begin{array}{l}
150=(2 / 3)(450 / 3)+(1+0.25)(100-(2 / 3) \times 90) \\
50=(2 / 3)(0)+(1+0.25)(100-(2 / 3) \times 90)
\end{array}\right. \\
\text { or } \quad\left[\begin{array}{c}
150 \\
50
\end{array}\right]=\frac{2}{3}\left[\begin{array}{c}
450 \\
3 \\
0
\end{array}\right]+\left(100-\frac{2}{3} \times 90\right)\left[\begin{array}{c}
1.25 \\
1.25
\end{array}\right]
\end{gathered}
$$

That is, after the firm changes its debt-equity ratio, the equityholders can always combine the new equity with other securities (e.g., money market) to create a "home-made equity" which will give exactly the same time-1 payoff of the old equity. ${ }^{3}$ We now have a capital structure irrelevancy proposition: changes in firms' debt-equity ratio will not affect equityholders' wealth (welfare), and equityholders' preferences toward variance are irrelevant. ${ }^{4}$ This result refutes the claims in the literature that "the use of debt rather than equity funds to finance a given venture may well increase the expected return to the owners, but only at the cost of increased dispersion of the outcomes" (Modigliani and Miller, 1958 [4], p. 262); "any gains from using more of what might seem to be cheaper debt capital would thus be offset by correspondingly higher cost of the now riskier equity capital" (Miller, 1988, p. 100) [5]; and "the lev-

\footnotetext{
${ }^{4} \mathrm{After}$ the firm changes its debt-equity ratio, the debtholders can also combine the new debt with other securities to create a home-made debt which will give exactly the same time-1 payoff of the old debt (i.e., debtholders' preferences toward variance are irrelevant). Thus, in complete markets, mean-variance analysis may not be meaningful.
} 
ered stockholders have better returns in good times than do unlevered stockholders but have worse returns in bad times, implying greater risk with leverage" (Ross, Westerfield and Jaffe, 2010 [6], p. 496). ${ }^{5}$

Example 3. Pricing Debt and Equity Contracts.

In Example 2, assume Equation (4) where Security 3 is a levered firm:

$$
\begin{aligned}
& \text { (Money Market (Security 1): } \\
& S_{0}^{1}=1=\frac{1}{1+0.25}\left(\frac{3}{4} \times 1.25+\frac{1}{4} \times 1.25\right) \\
& \text { Security } 2: S_{0}^{2}=5.2=\frac{1}{1+0.25}\left(\frac{3}{4} \times 8+\frac{1}{4} \times 2\right) \\
& \left\{\begin{array}{l}
E_{0}^{1^{\prime \prime}}=90=\frac{1}{1+0.25}\left(\frac{3}{4} \times \frac{450}{3}+\frac{1}{4} \times 0\right) \\
E_{0}^{2 \prime \prime}=90=\frac{1}{1+0.25}\left(\frac{3}{4} \times \frac{450}{3}+\frac{1}{4} \times 0\right) \\
E_{0}^{3^{\prime \prime}}=90=\frac{1}{1+0.25}\left(\frac{3}{4} \times \frac{450}{3}+\frac{1}{4} \times 0\right) \\
D_{0}^{4^{\prime}}=115=\frac{1}{1+0.25}\left(\frac{3}{4} \times 150+\frac{1}{4} \times 125\right) \\
D_{0}^{5^{\prime}}=115=\frac{1}{1+0.25}\left(\frac{3}{4} \times 150+\frac{1}{4} \times 125\right) \\
\vdots
\end{array}\right.
\end{aligned}
$$

Suppose that the firm moves to a more uncertain project, and its time-1 payoff is $\left[\begin{array}{l}900 \\ 100\end{array}\right]$ rather than $\left[\begin{array}{l}750 \\ 250\end{array}\right]$.

Then, Equation (4') becomes:

$$
\begin{aligned}
& \text { (Money Market (Security 1): } \\
& S_{0}^{1}=1=\frac{1}{1+0.25}\left(\frac{3}{4} \times 1.25+\frac{1}{4} \times 1.25\right) \\
& \text { Security } 2: S_{0}^{2}=5.2=\frac{1}{1+0.25}\left(\frac{3}{4} \times 8+\frac{1}{4} \times 2\right) \\
& \left\{\begin{array}{l}
E_{0}^{1 " \prime}=120=\frac{1}{1+0.25}\left(\frac{3}{4} \times \frac{600}{3}+\frac{1}{4} \times 0\right) \\
E_{0}^{2{ }^{\prime \prime \prime}}=120=\frac{1}{1+0.25}\left(\frac{3}{4} \times \frac{600}{3}+\frac{1}{4} \times 0\right) \\
E_{0}^{3 " \prime \prime}=120=\frac{1}{1+0.25}\left(\frac{3}{4} \times \frac{600}{3}+\frac{1}{4} \times 0\right) \\
D_{0}^{4 "}=100=\frac{1}{1+0.25}\left(\frac{3}{4} \times 150+\frac{1}{4} \times 50\right) \\
D_{0}^{5 "}=100=\frac{1}{1+0.25}\left(\frac{3}{4} \times 150+\frac{1}{4} \times 50\right)
\end{array}\right.
\end{aligned}
$$

It is found that when the firm moves from a more certain project (its time-1 payoff is either $\$ 750$ or $\$ 250$ ) to a more uncertain one (its time-1 payoff is either $\$ 900$ or $\$ 100$ ), the variance of the time-1 payoff of the firm (and the variance of the time- 1 payoff of the equity) increases, the time- 0 price of equity increases, but the time- 0 price of debt decreases. ${ }^{6}$ Also, this redistribution effect of wealth between debtholders and equityholders has nothing to do with their attitudes toward risk. These results and the results of Example 1 refute the claims that "there is a fundamental distinction between holding an option on an underlying asset and holding the underlying asset. If investors in the marketplace are risk-averse, a rise in the variability of the stock will decrease its market value" (Ross, Westerfield and Jaffe, 2010 [6], p. 689); and "in most financial settings, risk is a bad thing; you have to be paid to bear it. Investor in risky (high-beta) stocks demand higher expected rates of return. High-risk capital investment projects have correspondingly high costs of capital and have to beat higher hurdle rates to achieve positive NPV. For options it's the other way around" (Brealey, Myers and Allen, 2006 [7], p. 557).

Example 4. Pricing Convertible Bonds.

In Example 2, assume Equation (2) where Security 3 is a levered firm. Assume that one of the firm's riskless debts is changed into a convertible bond:

$$
\text { Security } 3:\left\{\begin{array}{c}
e_{0}^{1}=93.75=\frac{1}{1+0.25}\left(\frac{3}{4} \times \frac{(750-125)}{4}+\frac{1}{4} \times 0\right) \\
e_{0}^{3}=93.75=\frac{1}{1+0.25}\left(\frac{3}{4} \times \frac{(750-125)}{4}+\frac{1}{4} \times 0\right) \\
C B_{0}=118.75 \\
=\frac{1}{1+0.25}\left(\frac{3}{4} \times \frac{(750-125)}{4} \times 0\right) \\
D_{0}^{5}=100=\frac{1}{4} \times \frac{1}{1+0.25}\left(\frac{3}{4} \times 125+\frac{1}{4} \times 125\right)
\end{array}\right.
$$

Adding this convertible bond dilutes the time- 0 value of the equity (which decreases from 100 dollars to 93.75 dollars). The time- 0 price of the option (the right) of converting the bond into a share of equity is 18.75 (=

\footnotetext{
${ }^{5}$ In incomplete markets, after the firm changes its debt-equity ratio, the equityholders may not be able to create a home-made equity to replicate the time-1 payoff of the old equity. See Appendix B.

${ }^{6}$ Because the debtholders' time-1 payoff has an upper bound, they will not benefit if the more uncertain project succeeds, and they will suffer if the more uncertain project fails. Note that in some cases, the time- 0 price of a firm may decrease when the firm moves to a more uncertain project. See Appendix C.
} 
118.75 - 100) dollars.

Example 5. Pricing Different Contracts.

In Example 4, assume Equation (6) where Security 3 is a levered firm. Suppose that the firm's hiring an additional labor (a manager) can increase its time-1 payoff

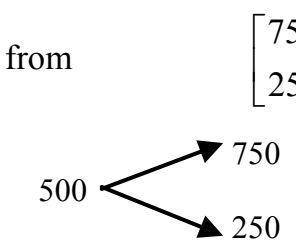

Security 3

50

$$
\left[\begin{array}{l}
750 \\
250
\end{array}\right] \text { to }\left[\begin{array}{l}
850 \\
300
\end{array}\right] \text { : }
$$

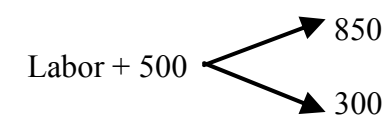

Security 3'
The time- 0 value of the whole firm will be 570 dollars, and the time- 0 value of the labor input will be 70 dollars:

$$
\left\{\begin{array}{l}
570=\frac{1}{1+0.25}\left(\frac{3}{4} \times 850+\frac{1}{4} \times 300\right) \\
70=\frac{1}{1+0.25}\left(\frac{3}{4} \times(850-750)+\frac{1}{4} \times(300-250)\right)
\end{array}\right.
$$

Note that different labor contractual arrangements will not affect the time- 0 prices of the labor input and the whole capital input (which includes equity, debt and convertible bond): ${ }^{7}$

Fixed-wage contract:

$$
\text { Security } 3^{\prime}:\left\{\begin{array}{l}
e_{0}^{1 \mathrm{f}}=98.4375=\frac{1}{1+0.25}\left(\frac{3}{4} \times \frac{(850-106.25-87.5)}{4}+\frac{1}{4} \times 0\right) \\
e_{0}^{2 \mathrm{f}}=98.4375=\frac{1}{1+0.25}\left(\frac{3}{4} \times \frac{(850-106.25-87.5)}{4}+\frac{1}{4} \times 0\right) \\
e_{0}^{3 \mathrm{f}}=98.4375=\frac{1}{1+0.25}\left(\frac{3}{4} \times \frac{(850-106.25-87.5)}{4}+\frac{1}{4} \times 0\right) \\
C B_{0}^{\mathrm{f}}=119.6875=\frac{1}{1+0.25}\left(\frac{3}{4} \times \frac{(850-106.25-87.5)}{4}+\frac{1}{4} \times 106.25\right) \\
D_{0}^{5 \mathrm{f}}=85=\frac{1}{1+0.25}\left(\frac{3}{4} \times 106.25+\frac{1}{4} \times 106.25\right) \\
\text { Labor }^{\mathrm{f}}=70=\frac{1}{1+0.25}\left(\frac{3}{4} \times 87.5+\frac{1}{4} \times 87.5\right)
\end{array}\right.
$$

Share contract (where the labor's share: $x=7 / 57$; the capital providers' share: $1-x=50 / 57$ ):

$$
\text { Security 3': }\left\{\begin{array}{l}
e_{0}^{1 \mathrm{~s}}=92.105263=\frac{1}{1+0.25}\left(\frac{3}{4} \times \frac{850(1-x)-300(1-x) / 2}{4}+\frac{1}{4} \times 0\right) \\
e_{0}^{2 \mathrm{~s}}=92.105263=\frac{1}{1+0.25}\left(\frac{3}{4} \times \frac{850(1-x)-300(1-x) / 2}{4}+\frac{1}{4} \times 0\right) \\
C B_{0}^{\mathrm{s}}=118.421052=\frac{1}{1+0.25}\left(\frac{3}{4} \times \frac{850(1-x)-300(1-x) / 2}{4}+\frac{1}{4} \times \frac{300(1-x)}{2}\right) \\
D_{0}^{5 \mathrm{~s}}=105.263158=\frac{1}{1+0.25}\left(\frac{3}{4} \times \frac{850(1-x)-300(1-x) / 2}{4}+\frac{1}{4} \times 0\right) \\
\text { Labor }^{\mathrm{s}}=70=\frac{1}{1+0.25}\left(\frac{3}{4} \times 850 x+\frac{1}{4} \times 300 x\right)
\end{array}\right)
$$

\footnotetext{
${ }^{7}$ With the assumption of certainty, Cheung (1968) [8] finds that different labor contractual arrangements will not affect the efficiency of resource allocation.
}

Mixed contract (where the labor obtains 50 dollars and has share: $y=3 / 53$, and capital providers' share is: $1-y=50 / 53)$ : 
Security $3^{\prime}:\left\{\begin{array}{l}e_{0}^{1 \mathrm{~m}}=95.518868=\frac{1}{1+0.25}\left(\frac{3}{4} \times \frac{(850-50)(1-y)-(300-50)(1-y) / 2}{4}+\frac{1}{4} \times 0\right) \\ e_{0}^{2 \mathrm{~m}}=95.518868=\frac{1}{1+0.25}\left(\frac{3}{4} \times \frac{(850-50)(1-y)-(300-50)(1-y) / 2}{4}+\frac{1}{4} \times 0\right) \\ C B_{0}^{\mathrm{m}}=119.103773=\frac{1}{1+0.25}\left[\frac{3}{4} \times \frac{(850-50)(1-y)-(300-50)(1-y) / 2}{4}+\frac{1}{4} \times \frac{(300-50)(1-y)}{2}\right] \\ D_{0}^{5 \mathrm{~m}}=94.339622=\frac{1}{1+0.25}\left(\frac{3}{4} \times \frac{(300-50)(1-y)}{2}+\frac{1}{4} \times \frac{(300-50)(1-y)}{2}\right) \\ \text { Labor }^{\mathrm{m}}=70=\frac{1}{1+0.25}\left(\frac{3}{4} \times(50+(850-50) y)+\frac{1}{4} \times(50+(300-50) y)\right)\end{array}\right]$

Suppose the firm moves to a more uncertain project, and its time-1 payoff is $\left[\begin{array}{c}1200 \\ 40\end{array}\right]$ rather than $\left[\begin{array}{l}850 \\ 300\end{array}\right]$, and assume that the labor is the first to get payment, the

$$
\text { Security 3": }\left\{\begin{array}{l}
e_{0}^{1 \mathrm{fr}^{\prime \prime}}=150.9375=\frac{1}{1+0.25}\left(\frac{3}{4} \times \frac{(1200-106.25-87.5)}{4}+\frac{1}{4} \times 0\right) \\
e_{0}^{2 \mathrm{f}^{\prime \prime}}=150.9375=\frac{1}{1+0.25}\left(\frac{3}{4} \times \frac{(1200-106.25-87.5)}{4}+\frac{1}{4} \times 0\right) \\
C B_{0}^{\mathrm{fr}^{\prime \prime}}=150.9375=\frac{1}{1+0.25}\left(\frac{3}{4} \times \frac{(1200-106.25-87.5)}{4}+\frac{1}{4} \times 0\right) \\
D_{0}^{5 \mathrm{ff}^{\prime \prime}}=63.75=\frac{1}{1+0.25}\left(\frac{3}{4} \times \frac{(1200-106.25-87.5)}{4}+\frac{1}{4} \times 0\right) \\
\text { Labor } \left.^{\mathrm{r}} \times 60.5=\frac{1}{4} \times 106.25+\frac{1}{4} \times 0\right)
\end{array}\right.
$$

common bondholder is the second to get payment, the convertible bondholder is the third to get payment, and the equityholder obtains the residual:

Fixed-wage contract:

Share contract (where labor share: $x=7 / 57$; capital providers share: $1-x=50 / 57$ ):

$$
\text { Security } 3^{\prime \prime}:\left\{\begin{array}{l}
e_{0}^{1 s^{\prime}}=138.157895=\frac{1}{1+0.25}\left(\frac{3}{4} \times \frac{1200(1-x)-300(1-x) / 2}{4}+\frac{1}{4} \times 0\right) \\
e_{0}^{2 s^{\prime}}=138.157895=\frac{1}{1+0.25}\left(\frac{3}{4} \times \frac{1200(1-x)-300(1-x) / 2}{4}+\frac{1}{4} \times 0\right) \\
e_{0}^{3 s^{\prime}}=138.157895=\frac{1}{1+0.25}\left(\frac{3}{4} \times \frac{1200(1-x)-300(1-x) / 2}{4}+\frac{1}{4} \times 0\right) \\
C B_{0}^{\mathrm{s}^{s^{\prime}}}=141.666667=\frac{1}{1+0.25}\left(\frac{3}{4} \times \frac{1200(1-x)-300(1-x) / 2}{4}+\frac{1}{4} \times \frac{40(1-x)}{2}\right) \\
D_{0}^{5 s^{\prime}}=82.45614=\frac{1}{1+0.25}\left(\frac{3}{4} \times \frac{300(1-x)}{2}+\frac{1}{4} \times \frac{40(1-x)}{2}\right) \\
\text { Labor }{ }^{s^{\prime}}=89.403508=\frac{1}{1+0.25}\left(\frac{3}{4} \times 1200 x+\frac{1}{4} \times 40 x\right)
\end{array}\right.
$$


Mixed contract (where the labor obtains 50 dollars and $\quad 1-y=50 / 53$ ): has share: $y=3 / 53$, and capital providers' share is:

$$
\text { Security 3": }\left\{\begin{array}{l}
e_{0}^{1 \mathrm{~m}^{\prime}}=145.047169=\frac{1}{1+0.25}\left(\frac{3}{4} \times \frac{(1200-50)(1-y)-(300-50)(1-y) / 2}{4}+\frac{1}{4} \times 0\right) \\
e_{0}^{2 \mathrm{~m}^{\prime}}=145.047169=\frac{1}{1+0.25}\left(\frac{3}{4} \times \frac{(1200-50)(1-y)-(300-50)(1-y) / 2}{4}+\frac{1}{4} \times 0\right) \\
e_{0}^{3 \mathrm{~m}^{\prime}}=145.047169=\frac{1}{1+0.25}\left(\frac{3}{4} \times \frac{(1200-50)(1-y)-(300-50)(1-y) / 2}{4}+\frac{1}{4} \times 0\right) \\
C B_{0}^{\mathrm{m}^{\prime}}=145.047169=\frac{1}{1+0.25}\left(\frac{3}{4} \times \frac{(1200-50)(1-y)-(300-50)(1-y) / 2}{4}+\frac{1}{4} \times 0\right) \\
D_{0}^{5 \mathrm{~m}^{\prime}}=70.754717=\frac{1}{1+0.25}\left(\frac{3}{4} \times \frac{(300-50)(1-y)}{2}+\frac{1}{4} \times 0\right) \\
\text { Labor }{ }^{\mathrm{m}^{\prime}}=77.056604=\frac{1}{1+0.25}\left(\frac{3}{4} \times(50+(1200-50) y)+\frac{1}{4} \times 40\right)
\end{array}\right.
$$

The time- 0 prices of the whole firm, the equity and the convertible bond will increase. The time- 0 price of the common bond will decrease. The time- 0 price of the labor input will decrease if it is under the fixed-wage contract. The time- 0 price of the labor input will increase if it is under the share or the mixed contracts.

\section{Concluding Remarks}

This paper has used the Arbitrage Theorem (Gordan Theorem) to show that first, all securities are derivatives for each other, and they are priced by the same risk neutral probability measure. Second, after the firm changes its debt-equity ratio, the equityholders can always combine the new equity with other existing securities to create a home-made equity which will give exactly the same time-1 payoff of the old equity. That is, we have a capital structure irrelevancy proposition: changes in firms' debtequity ratios will not affect equityholders' wealth (welfare), and equityholders' preferences toward variance are irrelevant. Third, when the firm moves from a more certain project to a more uncertain one, the time- 0 price of equity will increase, but (because the time-1 payoff of common bond has an upper bound) the time- 0 price of common bond will decrease. Fourth, different labor contractual arrangements will not affect the time- 0 price of labor input. When the firm moves from a more certain project to a more uncertain one, the time- 0 price of labor input will increase if it is under the share or the mixed contract.

\section{REFERENCES}

[1] F. Black and M. Scholes, "The Pricing of Options and Corporate Liabilities," Journal of Political Economy, Vol.
81, No. 3, 1973, pp. 637-654. doi:10.1086/260062

[2] J. Cox, S. Ross and M. Rubinstein, "Option Pricing: A Simplified Approach," Journal of Financial Economics, Vol. 7, No. 3, 1979, pp. 229-263. doi:10.1016/0304-405X(79)90015-1

[3] K. P. Chang, "A Reconsideration of the ModiglianiMiller Propositions," 2004. http://ssrn.com/abstract=657921

[4] F. Modigliani and M. Miller, "The Cost of Capital, Corporation Finance and the Theory of Investment," American Economic Review, Vol. 48, No. 3, 1958, pp. 261-297.

[5] M. Miller, "The Modigliani-Miller Propositions: After Thirty Years," Journal of Economic Perspectives, Vol. 2, No. 4, 1988, pp. 99-120. doi:10.1257/jep.2.4.99

[6] S. Ross, R. Westerfield and J. Jaffe, "Corporate Finance," McGraw-Hill, New York, 2010.

[7] R. Brealey, S. Myers and F. Allen, "Principles of Corporate Finance," McGraw-Hill, New York, 2006.

[8] S. Cheung, "Private Property Rights and Sharecropping," Journal of Political Economy, Vol. 76, No. 6, 1968, pp. 1107-1122. doi:10.1086/259477

[9] R. Litzenberger and H. Sosin, "The Theory of Recapitalizations and the Evidence of Dual Purpose Funds," Journal of Finance, Vol. 32, No. 5, 1977, pp. 1433-1455. doi:10.1111/j.1540-6261.1977.tb03346.x

[10] C. Huang and R. Litzenberger, "Foundations for Financial Economics," Elsevier Science Publishing, New York, 1988. 


\section{Appendix A}

In incomplete markets, securities may not be derivatives for each other, but with no arbitrage (System 2 of Theorem 4 has a solution), they will still be priced by the same (which may not be unique) risk neutral probability measure. For example, assume that only two securities (one of them is a money market with interest rate $r=$ 0.25 ) exist in a no-arbitrage, one-period, five states of nature world:

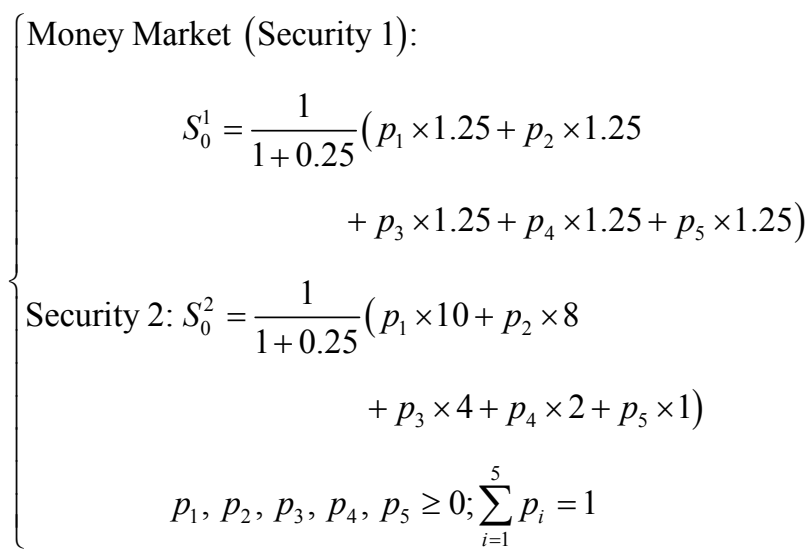

Suppose that there is a new security: Security 3 whose time-1 payoff is: $\quad \mathbf{c}=\left[\begin{array}{c}12.8 \\ 10.4 \\ 5.6 \\ 3.2 \\ 2\end{array}\right]$.

Because $\mathbf{c}$ lies in the subspace spanned by

$$
\mathbf{a}=\left[\begin{array}{c}
1.25 \\
1.25 \\
1.25 \\
1.25 \\
1.25
\end{array}\right] \text { and } \mathbf{b}=\left[\begin{array}{c}
10 \\
8 \\
4 \\
2 \\
1
\end{array}\right]
$$

(i.e., $\mathbf{c} \in S=\left\{\alpha \mathbf{a}+\beta \mathbf{b}: \alpha, \beta \in R^{1}\right\}$ ), the time-1 payoff of Security 3 can be derived (replicated) by those of Securities 1 and 2:

$$
\left[\begin{array}{c}
12.8 \\
10.4 \\
5.6 \\
3.2 \\
2
\end{array}\right]=(0.64)\left[\begin{array}{l}
1.25 \\
1.25 \\
1.25 \\
1.25 \\
1.25
\end{array}\right]+(1.2)\left[\begin{array}{c}
10 \\
8 \\
4 \\
2 \\
1
\end{array}\right]
$$

The time- 0 price of Security 3 is:

$S_{0}^{3}=(0.64) S_{0}^{1}+(1.2) S_{0}^{2}$, and with no arbitrage, the three securities are priced by the same risk probability measure:

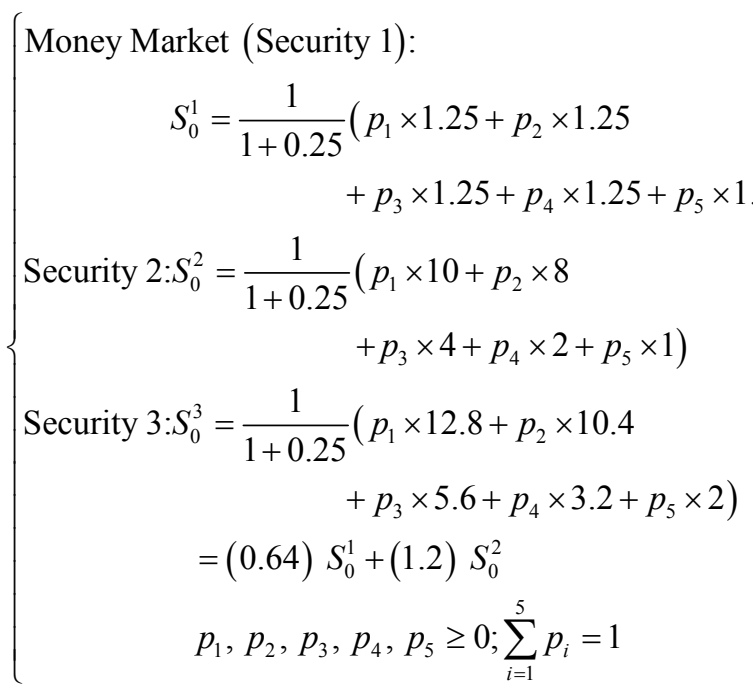

Suppose that the time-1 payoff of Security 3 is:

$$
\mathbf{c}^{\prime}=\left[\begin{array}{c}
11.25 \\
9.25 \\
5.25 \\
3.25 \\
2
\end{array}\right] \text {. }
$$

Because $\mathbf{c}^{\prime} \notin S=\left\{\alpha \mathbf{a}+\beta \mathbf{b}: \alpha, \beta \in R^{1}\right\}$, the time-1 payoff of Security 3 cannot be replicated by those of Securities 1 and 2. But with no arbitrage (System 2 of Theorem 4 has a solution), all the three securities will be priced by the same risk probability measure:

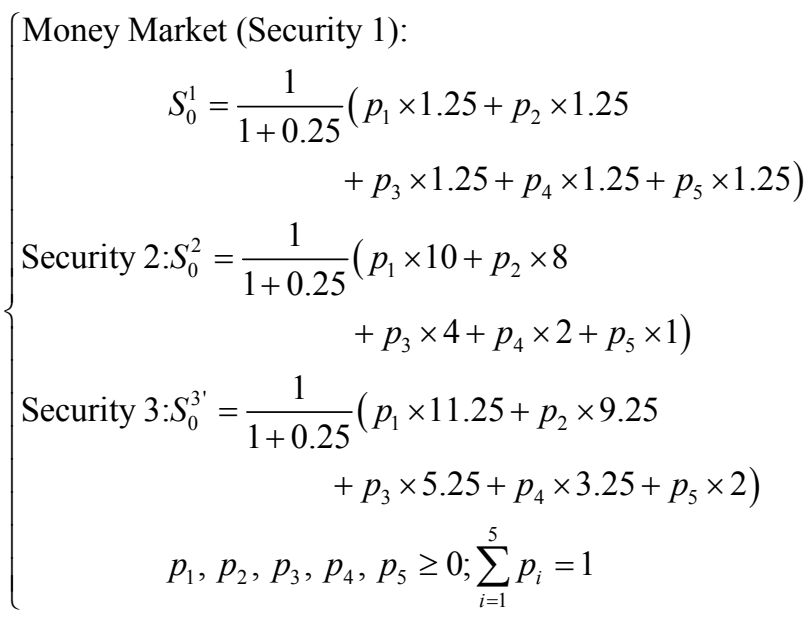

where $p_{1}, p_{2}, p_{3}, p_{4}, p_{5}$ may not be unique.

\section{Appendix B}

In incomplete markets, after the firm changes its debtequity ratio, the equityholders may not be able to create a home-made equity to replicate the time-1 payoff of the old equity. For example, assume that only two securities (one of them is a money market with interest rate $r=$ 
0.25) exist in a no-arbitrage, one-period, five states of nature world:

$$
\left\{\begin{array}{c}
\text { Money Market (Security 1): } \\
\qquad \begin{array}{c}
S_{0}^{1}=1=\frac{1}{1+0.25}\left(1.25 \times p_{1}+1.25 \times p_{2}+1.25 \times p_{3}\right. \\
+
\end{array} \\
\text { Security } 2: S_{0}^{2}=4=\frac{1}{1+0.25}\left(10 \times p_{4}+1.25 \times p_{5}\right) \\
\left.+4 \times p_{3}+2 \times p_{4}+1 \times p_{5}\right) \\
p_{1}, p_{2}, p_{3}, p_{4}, p_{5} \geq 0 ; \sum_{i=1}^{5} p_{i}=1
\end{array}\right.
$$

where the risk neutral probability can be

$$
\mathbf{p}^{\prime}=\left[\begin{array}{c}
0.2 \\
0.2 \\
0.2 \\
0.2 \\
0.2
\end{array}\right] \text { or } \mathbf{p}^{\prime \prime}=\left[\begin{array}{c}
7 / 90 \\
1 / 5 \\
3 / 5 \\
1 / 10 \\
1 / 45
\end{array}\right]
$$

Assume that Security 2 is an all equity firm and it plans to issue a riskless debt (debtholder pays 0.8 dollar at time 0 , and obtains 1 dollar at time 1$)$ :

By $\mathbf{p}^{\prime}$,

Security 2: $\left\{\begin{aligned} E_{0}^{\prime}=3.2=\frac{1}{1+0.25}(9 \times 0.2+7 \times 0.2+3 \times 0.2 \\ +1 \times 0.2+0 \times 0.2) \\ D_{0}^{\prime}=0.8=\frac{1}{1+0.25}(1 \times 0.2+1 \times 0.2+1 \times 0.2 \\ +1 \times 0.2+1 \times 0.2)\end{aligned}\right.$ or, by $\mathbf{p}^{\prime}$,

$$
\text { Security 2: }\left\{\begin{array}{r}
E_{0}^{\prime \prime}=3.2=\frac{1}{1+0.25}\left(9 \times \frac{7}{90}+7 \times \frac{1}{5}+3 \times \frac{3}{5}\right. \\
\left.+1 \times \frac{1}{10}+0 \times \frac{1}{45}\right) \\
D_{0}^{\prime \prime}=0.8=\frac{1}{1+0.25}\left(1 \times \frac{7}{90}+1 \times \frac{1}{5}+1 \times \frac{3}{5}\right. \\
\left.+1 \times \frac{1}{10}+1 \times \frac{1}{45}\right)
\end{array}\right.
$$

That is, recapitalization through issuing riskless debt does not change the market value of the firm (i.e., the time- 0 price of Security 2 is always 4 dollars), and the time- 0 prices of equity and debt are independent of the risk neutral probability measure used. Also, after the firm issues riskless debt, the equityholder can always create a home-made equity by combining the new equity ( $E_{0}^{\prime}$ or $\left.E_{0}^{\prime \prime}\right)$ with investing 0.8 dollar in the money market, which will give exactly the same time-1 payoff of the old equity:

$$
\mathbf{b}=\left[\begin{array}{c}
10 \\
8 \\
4 \\
2 \\
1
\end{array}\right]
$$

Suppose that the time-1 payoff of the debt is uncertain:

$$
\mathbf{d}_{1}=\left[\begin{array}{l}
3 \\
3 \\
3 \\
2 \\
1
\end{array}\right],
$$

and the time-1 payoff of the equity is:

$$
\mathbf{e}_{1}=\left[\begin{array}{l}
7 \\
5 \\
1 \\
0 \\
0
\end{array}\right] \text {. }
$$

Since $\mathbf{b} \notin S=\left\{\alpha \mathbf{a}+\beta \mathbf{e}_{1} ;: \alpha, \beta \in R^{1}\right\}$ where

$$
\mathbf{a}=\left[\begin{array}{c}
1.25 \\
1.25 \\
1.25 \\
1.25 \\
1.25
\end{array}\right] \text { and } \mathbf{b}=\left[\begin{array}{c}
10 \\
8 \\
4 \\
2 \\
1
\end{array}\right],
$$

b cannot be replicated by $\mathbf{a}$ and $\mathbf{e}_{1}$. That is, the equityholder cannot combine the new equity $\mathbf{e}_{1}$ with the money market to create a home-made equity to replicate the time-1 payoff of the old equity:

$$
\mathbf{b}=\left[\begin{array}{c}
10 \\
8 \\
4 \\
2 \\
1
\end{array}\right] .
$$

Also, with different risk neutral probability measures:

By $\mathbf{p}^{\prime}$,

$$
\text { Security 2: }\left\{\begin{array}{r}
e_{0}^{\prime}=2.08=\frac{1}{1+0.25}(7 \times 0.2+5 \times 0.2+1 \times 0.2 \\
+0 \times 0.2+0 \times 0.2) \\
d_{0}^{\prime}=1.92=\frac{1}{1+0.25}(3 \times 0.2+3 \times 0.2+3 \times 0.2 \\
+2 \times 0.2+1 \times 0.2)
\end{array}\right.
$$


By p",

$$
\text { Security 2: }\left\{\begin{array}{r}
e_{0}^{\prime \prime=1.71555=\frac{1}{1+0.25}(}\left(7 \times \frac{7}{90}+5 \times \frac{1}{5}+1 \times \frac{3}{5}\right. \\
\left.+0 \times \frac{1}{10}+0 \times \frac{1}{45}\right) \\
d_{0}^{\prime \prime}=2.28444=\frac{1}{1+0.25}\left(3 \times \frac{7}{90}+3 \times \frac{1}{5}+3 \times \frac{3}{5}\right. \\
\left.+2 \times \frac{1}{10}+1 \times \frac{1}{45}\right)
\end{array}\right.
$$

The time- 0 price of Security 2 can be the sum of $e_{0}^{\prime}$ and $d_{0}^{\prime \prime}$ (which is equal to $4.36444>4$ ), and with no arbitrage,

$$
\begin{aligned}
& \text { (Money Market (Security 1): } \\
& \begin{array}{c}
S_{0}^{1}=1=\frac{1}{1+0.25}\left(1.25 \times p_{1}+1.25 \times p_{2}+1.25 \times p_{3}\right. \\
\left.+1.25 \times p_{4}+1.25 \times p_{5}\right) \\
e_{0}^{\prime}=2.08=\frac{1}{1+0.25}\left(7 \times p_{1}+5 \times p_{2}+1 \times p_{3}\right. \\
\left.+0 \times p_{4}+0 \times p_{5}\right)
\end{array} \\
& \text { Security } 2:\left\{d_{0}^{\prime \prime}=2.28444\right. \\
& =\frac{1}{1+0.25}\left(3 \times p_{1}+3 \times p_{2}+3 \times p_{3}\right. \\
& \left.+2 \times p_{4}+1 \times p_{5}\right) \\
& p_{1}, p_{2}, p_{3}, p_{4}, p_{5} \geq 0 ; \sum_{i=1}^{5} p_{i}=1
\end{aligned}
$$

where the risk neutral probability can be

$$
\left[\begin{array}{c}
0.12127 \\
0.24921 \\
0.50507 \\
0.10445 \\
0.02
\end{array}\right] \text { or }\left[\begin{array}{c}
0.10984 \\
0.25635 \\
0.54936 \\
0.02445 \\
0.06
\end{array}\right] \text {. }
$$

If this is the case, then with no arbitrage, the time- 0 price of Security 2 in Equation (B1) will be adjusted to 4.36444 dollars in the first place (see also Litzenberger and Sosin, 1977 [9]; and Huang and Litzenberger, 1988 [10], pp. 128-129):

$$
\left\{\begin{aligned}
& \text { Money Market }(\text { Security } 1): \\
& S_{0}^{1}=1=\frac{1}{1+0.25}\left(1.25 \times p_{1}+1.25 \times p_{2}+1.25 \times p_{3}\right. \\
&\left.+1.25 \times p_{4}+1.25 \times p_{5}\right)
\end{aligned}\right.
$$

where $p_{1}, p_{2}, p_{3}, p_{4}, p_{5}$ may not be unique.

\section{Appendix C}

In some cases, the time- 0 price of a firm may decrease when the firm moves to a more uncertain project. For example, assume a firm exists in a no-arbitrage, oneperiod, two states of nature world (where the market interest rate is: $r=0.25$ ):

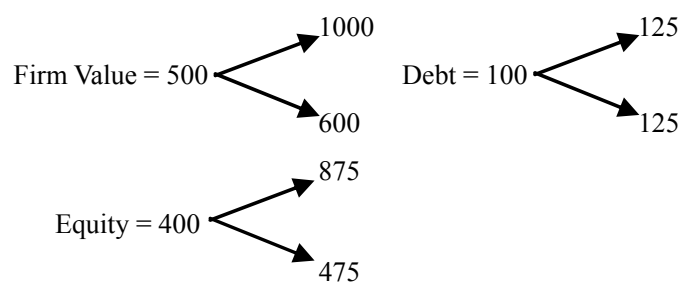

That is, the unique risk neutral probability for this world is:

$$
\left[\begin{array}{c}
1 / 16 \\
15 / 16
\end{array}\right],
$$

and

$$
=\left\{\begin{array}{l}
\text { Firm value } \\
\text { Equity: } 400=\frac{1}{1+0.25}\left(\frac{1}{16} \times 875+\frac{15}{16} \times 475\right) \\
\text { Debt: } 100=\frac{1}{1+0.25}\left(\frac{1}{16} \times 125+\frac{15}{16} \times 125\right)
\end{array}\right.
$$

Suppose the firm moves to a more uncertain project, and its time-1 payoff is

$$
\begin{aligned}
& {\left[\begin{array}{c}
2000 \\
100
\end{array}\right]} \\
& {\left[\begin{array}{c}
1000 \\
600
\end{array}\right] .}
\end{aligned}
$$

instead of

Then, the time- 0 prices of the whole firm, the equity and the debt decrease:

\section{Firm value}

$$
=\left\{\begin{array}{l}
\text { Equity: } 93.75=\frac{1}{1+0.25}\left(\frac{1}{16} \times 1875+\frac{15}{16} \times 0\right) \\
\text { Debt: } 81.25=\frac{1}{1+0.25}\left(\frac{1}{16} \times 125+\frac{15}{16} \times 100\right)
\end{array}\right.
$$

Since no one (especially, the equityholder) benefits, the firm will not move to this more uncertain project, and Equation (C2) does not exist. 